\title{
Psychological morbidity is the main predictor of quality of life among caregivers of individuals in first-episode psychosis: data from a year-long longitudinal study in Brazil
}

\author{
Rita de C. Jorge, ${ }^{1}$ (iD Hugo Cogo-Moreira, ${ }^{2}$ Ary G. Araripe Neto, ${ }^{3}$ Ana C. Chaves ${ }^{1}$ \\ ${ }^{1}$ Programa de Assistência e Pesquisa ao Primeiro Episódio Psicótico (PEP), Departamento de Psiquiatria, Escola Paulista de Medicina (EPM), \\ Universidade Federal de São Paulo (UNIFESP), São Paulo, SP, Brazil. ${ }^{2}$ Departamento de Psiquiatria e Psicologia Médica, EPM, UNIFESP, \\ São Paulo, SP, Brazil. ${ }^{3}$ Programa de Esquizofrenia (PROESQ), Departamento de Psiquiatria e Psicologia Médica, EPM, UNIFESP, São Paulo, \\ $S P$, Brazil.
}

\begin{abstract}
Objective: To investigate quality of life (QoL) and QoL predictors among caregivers of individuals in first-episode psychosis (FEP).

Methods: This longitudinal study investigated predictors of QoL in caregivers of 80 individuals in FEP over a 1-year follow-up period, measured using a single component extracted from the 36-item ShortForm Health Survey (SF-36).

Results: Mediation analysis demonstrated that, at 1 year, high scores in the Self-Report Questionnaire (SRQ-20) were associated with high scores on the negative sub-scale of the Experience of Caregiving Inventory $(\mathrm{ECl})$, which was also associated with low scores in the Essential Quality of Life (Essential QoL) component extracted from the SEF-36. Clinically, the resulting association indicates that depression and anxiety symptoms in caregivers at baseline are predictors of their 1-year quality of life, based on self-assessment of the caregiving experience.

Conclusion: Supporting an individual in FEP can have a negative impact on QoL. Maintaining caregivers' mental health and subjective evaluation of the caregiving experience must be primary goals of FEP services. Complementary studies of FEP caregivers' QoL can support the design of personalized interventions in the near future.
\end{abstract}

Keywords: Psychotic disorders; caregivers; quality of life

\section{Introduction}

Severe mental illness destabilizes a patient's family structures. Subjective assessment of a family member's caregiving experience is an important predictor of their wellbeing. ${ }^{1}$ The caregiving experience involves both negative and positive aspects, such as distress and reward. ${ }^{2,3}$ Furthermore, the relationship between caregivers and patients may be different in acute and chronic phases of disease. Acute phases are associated with better stress management by the caregiver and reduced psychological distress. Data on this association, however, are conflicting. ${ }^{1,4}$

First-episode psychosis (FEP) is defined as the first time an individual demonstrates severe psychotic symptoms, such as delusions, hallucinations, disordered thought, and catatonia, which cause suffering or impair functioning. ${ }^{5}$ FEP is not a diagnostic category, and is most helpful as a qualifier used typically to describe individuals at the beginning of a psychotic disorder or early stages of treatment. ${ }^{5}$ FEP is the time in which most psychotic patients

Correspondence: Rita de Cássia Ferreira de Araújo Jorge, Departamento de Psiquiatria, Escola Paulista de Medicina, Universidade Federal de São Paulo, Rua Major Maragliano, 241, Prédio Acadêmico, Vila Mariana, CEP 04017-030, São Paulo, SP, Brazil.

E-mail: ritajorge@icloud.com

Submitted May 24 2018, accepted Sep 04 2018, Epub Feb 182019. and their caregivers seek mental health services. ${ }^{6,7}$ Considering most individuals with psychotic disorders require long-term professional care management, preferably in outpatient regimens, caregivers play a key role in their recovery.

The primary caregiver is a friend, family member, or hired professional responsible for providing care to an ill individual. Becoming a primary caregiver involves dedication of time, energy, money, and emotional effort, which can lead to a significant burden. ${ }^{8}$ This burden may objectively or subjectively impact the caregiver's wellbeing and quality of life (QoL). ${ }^{9}$ Caregivers are considered fundamental for assessing, treating, and recovering from schizophrenia, and therefore must be given support, information, assessment of psychological morbidity - and, if needed, treatment - by a specialized FEP service throughout the patient's treatment. ${ }^{1}$

The concept of QoL encompasses self-assessed holistic parameters of one's life beyond the presence or absence of disease. It involves access to employment, family life,

How to cite this article: Jorge $\mathrm{RC}$, Cogo-Moreira $\mathrm{H}$, Araripe Neto AG, Chaves AC. Psychological morbidity is the main predictor of quality of life among caregivers of individuals in first-episode psychosis: data from a year-long longitudinal study in Brazil. Braz J Psychiatry. 2019;41:403-410. http://dx.doi.org/10.1590/1516-44462018-0169 
political stability, and opportunity. ${ }^{10}$ The World Health Organization (WHO) defines QoL as "individuals' perception of their position in life in the context of the culture and value systems in which they live and in relation to their goals, expectations, standards and concerns." ${ }^{11}$ Caregivers of individuals with different diseases usually score lower in QoL than non-caregivers worldwide. ${ }^{12,13}$

Caregivers to schizophrenic patients experience different levels of stress and QoL in different contexts across the world. ${ }^{14-16}$ Family members of individuals in FEP have been found to experience distress and difficulties; their psychological well-being was associated with their appraisal of the disease. ${ }^{7}$ On the other hand, caregiver overload is associated with a lower QoL and high levels of psychological morbidity. ${ }^{17}$

The goal of this study was to investigate the QoL of 80 caregivers to individuals in FEP admitted to a public outpatient service and assess factors that predict their QoL at 1-year follow-up. This is the first study on QoL of caregivers of individuals in FEP in Brazil.

\section{Methods}

\section{Setting}

This longitudinal study was performed in individuals in FEP and their caregivers, between 2009 and 2011, at Programa de Assistência e Pesquisa ao Primeiro Episódio Psicótico (PEP), Universidade Federal de São Paulo (UNIFESP), Brazil. The clinic offers structured, comprehensive, long-term treatment. Both patients and caregivers undergo several steps of evaluation and individual and group interventions by a multidisciplinary team composed of a psychiatrist, psychologists, social workers, and occupational therapists, which deals not only with pharmacotherapy of FEP but also education, labor, and relationship aspects. Most patients had been referred from the psychiatric emergency department of a large public university hospital belonging to UNIFESP and serving low-income communities.

This study was approved by the local research ethics committee (opinion no. 0738/08).

\section{Sample description}

The sample included 80 patients and their caregivers. The inclusion criteria were: patient in FEP ${ }^{18}$; age 15 to 35 years; no more than 3 months of previous treatment with antipsychotics; and having a caregiver present at the clinic. Candidate patients were screened for at least one psychotic symptom such as delusions, disordered thought, or catatonia. Formal diagnoses, among the broad category of psychotic disorders, were given by psychiatrists based on the DSM-IV, ${ }^{19}$ reviewed by a case management team of psychiatry specialists, and confirmed by a second psychiatrist and FEP specialist. The caregivers varied broadly in age (18 or older), lived with the patient or provided direct and constant assistance, and were unpaid. All caregivers agreed to the terms of this study by providing written informed consent for themselves and the patients. The sample excluded caregivers who experienced dementia or decompensated mental illness or were pregnant.

\section{Instruments}

The demographic characteristics of patients and caregivers were collected through structured questionnaires. Patients were diagnosed using the Structured Clinical Interview I (SCID-I) ${ }^{19}$ based on DSM-IV criteria for psychotic disorders and were evaluated using the Positive and Negative Syndrome Scale (PANSS). ${ }^{20,21}$ Caregivers were evaluated using the 36-item Short-Form Health Survey (SF-36), ${ }^{22}$ Experience of Caregiving Inventory (ECI), ${ }^{23}$ and 20-item Self-Report Questionnaire (SRQ-20). ${ }^{24}$

The SF-36 is a self-assessed measure of QoL as related to eight general health concepts and their current impact on one's activities. It is the most widely used scale of QoL worldwide and has been validated in more than 50 countries. The SF-36 evaluates physical and mental aspects and has numerous applications in medical research, such as assessing burden and the benefits brought by interventions. 22,25

The $\mathrm{ECl}$ was designed to assess a caregiver's perception of the impact of caring for patients with severe mental illness. This instrument broadly describes the caregiving experience by evaluating both positive and negative aspects and substituting notions of burden and suffering for a stress-coping model. ${ }^{23}$ Higher scores for the negative sub-scale are associated with a worse caregiving experience, while high scores for the positive sub-scale are associated with more reward and positive aspects. ${ }^{26}$ The scale was validated in Brazilian Portuguese during the first stage of this study and demonstrated good psychometric properties, with Cronbach's alpha $=0.95$ and subscale scores between 0.57 and $0.94 .^{27}$

The SRQ-20 is a tool to screen for psychiatric morbidity in non-psychotic disorders, mainly anxiety and depression. ${ }^{24}$

Although the scales were designed for self-assessment, they were administered directly by an interviewer due to the low educational level of the caregiver sample. The interviewer was trained by the study's first author to apply the scales in a fashion blinded to the patients' mental health outcome.

\section{Statistical analysis}

The search for predictors of caregiver QoL was based on the effect of SRQ-20, ECI, and PANSS scores on the SF36 , i.e., on the correlation between depression or anxiety symptoms in the caregivers; their assessment of the caregiving experience; the severity of the patients' symptoms; and the caregivers' QoL. The relationship between variables was determined through bivariate correlations, using the sum of positive responses on the SRQ-20; positive and negative $\mathrm{ECl}$ scores; general positive and negative PANSS scores; and eight domains of the SF-36. Spearman correlation was used in case of non-normal distribution of variables, while Pearson correlation was used in case of normal distribution (according to the KolmogorovSmirnov test). Subsequently, two linear regression models were constructed: one with crude and one with adjusted 
covariance. Bartlett's sphericity test was used to test the hypothesis that the eight SF-36 domains were not associated with one other. A significant test value $(p<0.05)$ led to rejection of the null hypothesis, indicating that principal component analysis (PCA) had been performed correctly, given the strong interrelationships with the SF-36 domains. PCA was used to extract a single QoL measure. PCA is not a technique for construct validation, but a mathematical strategy to handle many measurements of the same phenomenon by reducing them to simpler components; it was used to reduce the complexity of the interrelationships among the eight SF-36 domains to a smaller number of combinations. Two principal components were extracted: the first with an eigenvalue of 4.359 (accounting for $54.49 \%$ of data variance) and the second with an eigenvalue of 1.062 (13.26\% of variance). According to Kaiser's criteria, only components with an eigenvalue $>1$ should be retained (Table 1). Visual inspection of the scree plot as proposed by Cattell ${ }^{28}$ suggested retention of a single component. After pooling this information, a component was extracted by interpreting the visual inspection of the scree plot in conjunction with the variance of the second component, which proved substantially lower (13.26\%). This single component was denoted Essential QoL and employed in this study as a measure of QoL data and outcome of the regression models outlined below (mediation and moderation). The individual scores on the SF-36 domains are also given below for comparison with other studies.

We used a review of the literature to select potential predictors of lower caregiver QoL. ${ }^{1,17,29}$ A linear regression model was constructed to assess the prediction power of the three variables at baseline on Essential QoL measured at 1-year follow-up, namely: number of symptoms on SRQ20 , negative subscale of $\mathrm{ECl}$, and caregiver as patient's mother or otherwise. One further hypothesis was tested to clarify the relationships among these constructs: whether the effect of the SRQ-20 score measured at baseline is transmitted to QoL of caregivers at 1-year follow-up through the score on the negative subscale of the $\mathrm{ECI}$ (mediation effect) (Figure 1).

Mediation models were tested via PROCESS. ${ }^{30}$ The $\mathrm{ECl}$ measure at baseline was included in the model as a covariate. In accordance with recommendations by Hayes, ${ }^{31}$ the indirect effect of 10,000 bootstrap replications was used to produce an empirical representation of the sample distribution of the indirect effect, where 0 does not lie between the lower and upper bounds, and therefore it must be assumed with $95 \%$ confidence that the indirect effect is not 0 .

\section{Clinical and sociodemographic characteristics}

Baseline

Eighty patients and their caregivers were included in this study. The sociodemographic characteristics of patients are described in Table 2, and those of caregivers in Table 3. Among caregivers, $33.8 \%$ scored positive in the SRQ-20 for non-psychotic psychiatric disorders, even though only $10 \%$ of them were in treatment at the start of

Table 1 Total variance explained by the eight 36-item Short-Form Health Survey (SF-36) domains

\begin{tabular}{|c|c|c|c|c|c|c|c|}
\hline \multirow[b]{2}{*}{ Component } & \multicolumn{3}{|c|}{ Initial eigenvalues } & \multicolumn{3}{|c|}{ Extraction sums of square } & \multirow[b]{2}{*}{ Rotation sums of squared loadings } \\
\hline & Total & $\%$ variance & $\%$ cumulative & Total & $\%$ variance & $\%$ cumulative & \\
\hline 1 & 4.359 & 54.493 & 54.493 & 4.359 & 54.493 & 54.493 & 4.036 \\
\hline 2 & 1.062 & 13.269 & 67.762 & 1.062 & 13.269 & 67.762 & 3.112 \\
\hline 3 & 0.653 & 8.157 & 75.919 & & & & \\
\hline 4 & 0.56 & 6.994 & 82.913 & & & & \\
\hline 5 & 0.463 & 5.794 & 88.706 & & & & \\
\hline 6 & 0.385 & 4.813 & 93.519 & & & & \\
\hline 7 & 0.264 & 3.298 & 96.817 & & & & \\
\hline 8 & 0.255 & 3.183 & 100 & & & & \\
\hline
\end{tabular}

Extraction method: principal component analysis.

* When components are correlated, sums of squared loadings cannot be added to obtain total variance.

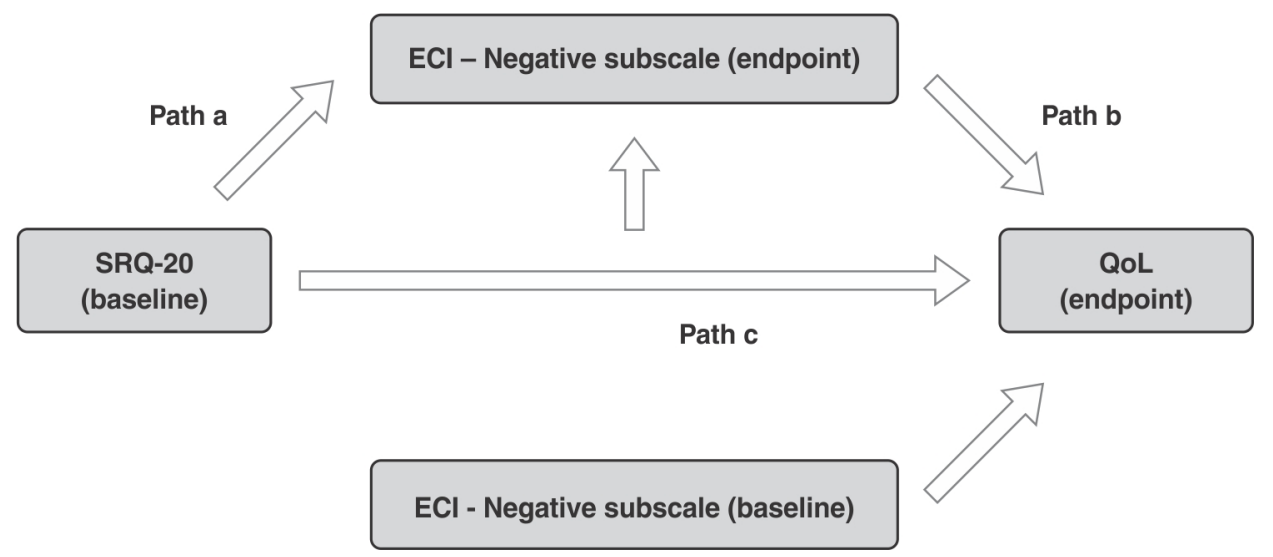

Figure 1 Mediation model. ECl = Experience of Caregiving Inventory; QoL = quality of life; SRQ-20 = Self-Report Questionnaire. 
Table 2 Profile of patients in first-episode psychosis

\begin{tabular}{|c|c|c|}
\hline & $\begin{array}{c}\text { Baseline } \\
(n=80)\end{array}$ & $\begin{array}{c}\text { 1-year follow-up } \\
(n=54,67.5 \%)\end{array}$ \\
\hline \multicolumn{3}{|l|}{ Sociodemographic data } \\
\hline Gender, male & 60.0 & 56.0 \\
\hline Age (years) & $23.68(6.75)$ & $23.57(6.45)$ \\
\hline Marital status, single & 83.8. & 85.2 \\
\hline Education (years) & $10.61(3.33)$ & $10.89(3.27)$ \\
\hline Currently studying & 75.0 & 37.0 \\
\hline Currently working & 23.7 & 27.8 \\
\hline \multicolumn{3}{|l|}{ Psychiatric background } \\
\hline Current drug use & 12.5 & 11.5 \\
\hline Present cannabis use & 11.2 & 7.7 \\
\hline Present cocaine use & 2.6 & 1.9 \\
\hline Current alcohol abuse & 17.3 & 9.6 \\
\hline Alcohol dependence & 0.0 & 3.8 \\
\hline \multicolumn{3}{|l|}{ Psychiatric scale measures } \\
\hline \multicolumn{3}{|l|}{ SCID-I diagnosis } \\
\hline Bipolar disorder & 30.7 & 33.4 \\
\hline Paranoid schizophrenia & 23.1 & 48.1 \\
\hline Psychotic depression & 13.5 & 9.3 \\
\hline psychosis & 0.0 & 5.6 \\
\hline Schizophreniform & & \\
\hline disorder & 23.1 & 0.0 \\
\hline Psychotic disorder NOS & 0.0 & 3.7 \\
\hline Brief psychotic disorder & 5.8 & 0.0 \\
\hline Schizoaffective disorder & 3.8 & 0.0 \\
\hline \multicolumn{3}{|l|}{ PANSS scores } \\
\hline Positive scale & $18.58(4.73)$ & $12.19(5.59)$ \\
\hline $\begin{array}{l}\text { Negative scale } \\
\text { General }\end{array}$ & $21.96(7.74)$ & $16.74(6.86)$ \\
\hline psychopathology & $39.35(8.10)$ & $32.07(8.30)$ \\
\hline
\end{tabular}

Data presented as \% or mean (standard deviation).

NOS $=$ not otherwise specified; PANSS = Positive and Negative Syndrome Scale; SCID-I = Structured Clinical Interview I.

the study. Caregivers had high scores in the ECI positive subscale and low to moderate scores in the negative subscale, which indicates they experienced more positive than negative aspects of caregiving. According to the caregivers, the caregiving experience was most impacted by the patients' challenging behavior, negative symptoms, and disrupted access to health services. The caregivers' QoL measured by the SF-36 had its lowest scores in the domains of role-emotional, vitality, and pain (Table 3). There was a positive correlation between the SRQ-20 and the negative subscale of the $\mathrm{ECl}(r=0.319 ; \mathrm{p}=$ 0.004 ), indicating that depression and anxiety symptoms in the caregivers were associated with a worse caregiving experience.

\section{One-year follow-up}

Overall, 55 caregivers and 54 patients completed 1-year follow-up. The main reasons for discontinuation were treatment default and loss of contact with the research team. There were no statistically significant changes in gender, age, and educational level between baseline $(n=80)$ and follow-up. Greater family income, better QoL at baseline, and the caregiver being the patient's mother contributed to adherence to the study.

At follow-up, all patients remained within the category of psychotic disorders, $70 \%$ of which kept the same
Table 3 Profile of caregivers of patients in first-episode psychosis

\begin{tabular}{ccc}
\hline & $\begin{array}{c}\text { Baseline } \\
(\mathrm{n}=80)\end{array}$ & $\begin{array}{c}\text { 1-year follow-up } \\
(\mathrm{n}=55,68.75 \%)\end{array}$ \\
\hline $\begin{array}{c}\text { Sociodemographic data } \\
\text { Gender, female }\end{array}$ & 76.3 & 81.8 \\
Age (years) & $46.61(11.69)$ & $49.15(11.51)$ \\
Mother of patient & 58.0 & 63.0 \\
Marital status & & \\
$\quad$ Married & 57.6 & 60.0 \\
Divorced & 21.3 & 20.0
\end{tabular}

Education, employment, and income

$\begin{array}{lcc}\text { Education (years) } & 9.3(4.57) & 10.8(3.40) \\ \text { Currently working } & 62.5 & 60.0 \\ \text { Monthly income } & & \\ \text { In local currency }(\mathrm{R} \$) & 1,890.00(1,535) & 2,174.00(1,519) \\ \text { In minimum wages } & 3.59(2.65) & 3.91(2.68) \\ \text { Low income } & 76.3 & 67.2\end{array}$

Perceived family environment

Serious domestic event

in 12 months before FEP

46.0

44.4

Psychiatric background

In psychiatric treatment

Current alcohol use

Current alcohol abuse

Current drug use

Family history of mental

illness

$\begin{array}{cc}8.8 & 7.3 \\ 16.3 & 27.1 \\ 1.3 & 1.8 \\ 1.3 & 0.0\end{array}$

Minor psychiatric disorder screening by SRQ-20

Positive 33.8

58.2

Quality of life scores by SF-36 domain

Physical functioning $\quad 69.87(25.20) \quad 68.36(21.62)$

$\begin{array}{lll}\text { Role-physical } & 75.62(34.89) & 80.00(34.15)\end{array}$

Bodily pain $\quad 63.37(26.21) \quad 62.76(24.86)$

General health $\quad 66.60(19.35) \quad 67.98(21.74)$

Vitality $\quad 68.90(27.70) \quad 66.09(20.33)$

Social functioning $\quad 62.31(23.24) \quad 79.31(23.35)$

Role-emotional $\quad 53.74(43.57) \quad 78.78(32.93)$

Mental health $\quad 63.95(23.48) \quad 69.74(19.48)$

Experience of caregiving by $\mathrm{ECl}$ total score

Negative $\quad 84.54(38.88) \quad 59.35(44.03)$

Positive $\quad 31.29(11.19) \quad 27.13(12.56)$

Data presented as \% or mean (standard deviation).

$\mathrm{ECl}=$ Experience of Caregiving Inventory; SF-36 = Short-Form 36; SRQ-20 = Self-Report Questionnaire.

diagnosis from baseline. The increase in schizophrenia diagnoses and the decrease in symptom severity, measured respectively by SCID-I and PANSS, were statistically significant after follow-up (Table 4).

The caregiving experience was rated as less negative, but also less positive, at 1-year follow-up. Upon testing the variables through Pearson correlations, we found that high negative scores on the PANSS were associated with worse results in the negative subscale of the $\mathrm{ECl}$. This means that when patients presented with more severe negative symptoms, caregivers experienced a more negative caregiving experience. QoL scores showed significant improvement in the role-emotional, social functioning, and mental health domains, while pain had the lowest score (Table 4). 
Table 4 Comparison of patient and caregiver groups that started and completed the study $(n=55)$

\begin{tabular}{|c|c|c|c|c|c|c|}
\hline & Baseline & 1-year follow up & Test value & df & $p$-value & Effect size* \\
\hline \multicolumn{7}{|l|}{ Caregiver group } \\
\hline \multicolumn{7}{|l|}{ Employment and income } \\
\hline Currently working & $33(60)$ & $35(63.6)$ & $0.167^{\ddagger}$ & 1 & 0.687 & $2.00(0.36-10.91)$ \\
\hline \multicolumn{7}{|l|}{ Perceived family environment } \\
\hline Serious event in 12 months before FEP & $23(41.8)$ & $10(18.2)$ & $8.471^{\ddagger}$ & 1 & 0.002 & $7.50(1.71-32.79)$ \\
\hline \multicolumn{7}{|l|}{ Psychiatric background } \\
\hline In psychiatric treatment & $4(7.3)$ & $6(10.9)$ & $0.5^{\ddagger}$ & 1 & 0.5 & - \\
\hline \multicolumn{7}{|l|}{ Minor psychiatric disorder screening by SRQ-20 } \\
\hline Number of positive responses, mean (SD) & $5.71(4.16)$ & $4.98(4.08)$ & $-1.811^{\dagger}$ & & 0.071 & 0.17 \\
\hline \multicolumn{7}{|c|}{ Quality of life scores by SF-36 domain, mean (SD) } \\
\hline Role-emotional & $51.51(41.97)$ & 78.78 (32.93) & $-3.949^{\dagger}$ & & $<0.001$ & 0.37 \\
\hline Role-physical & 79.09 (32.54) & $80(34.15)$ & $-0.188^{\dagger}$ & & 0.883 & 0.02 \\
\hline Social functioning & $69.54(26.10)$ & 79.31 (23.35) & $-2.125^{\dagger}$ & & 0.033 & 0.20 \\
\hline Physical functioning & $72.18(22.76)$ & $68.36(21.62)$ & $-1.718^{\dagger}$ & & 0.086 & 0.16 \\
\hline Bodily pain & $64.18(27.07)$ & $62.76(24.86)$ & $-0.557^{\dagger}$ & & 0.592 & 0.05 \\
\hline General health & $69.52(16.86)$ & $67.98(21.74)$ & $-0.314^{\dagger}$ & & 0.761 & 0.03 \\
\hline Mental health & $64.72(22.00)$ & $69.74(19.48)$ & $-2.15^{\dagger}$ & & 0.027 & 0.20 \\
\hline Vitality & $62.36(22.80)$ & $66.09(20.33)$ & $-1.228^{\dagger}$ & & 0.218 & 0.12 \\
\hline \multicolumn{7}{|c|}{ Experience of caregiving by $\mathrm{ECl}$ scores, mean (SD) } \\
\hline Negative total score & $85.42(37.18)$ & 59.35 (44.03) & $-4.433^{\dagger}$ & & $<0.001$ & 0.42 \\
\hline Positive total score & $31.55(10.48)$ & $27.13(12.56)$ & $2.991^{\S}$ & 54 & 0.004 & 0.38 \\
\hline \multicolumn{7}{|l|}{ Patient group } \\
\hline \multicolumn{7}{|l|}{ Psychiatric background } \\
\hline Present drug dependence & $9(16.7)$ & $6(11.1)$ & $0.571^{*}$ & 1 & 0.453 & $2.50(0.48-12.88)$ \\
\hline Cannabis & $7(13.0)$ & $5(9.3)$ & $0.167^{\ddagger}$ & 1 & 0.688 & $2.00(0.36-10.91)$ \\
\hline Cocaine & $5(9.3)$ & $2(3.7)$ & $0.8^{\ddagger}$ & 1 & 0.375 & $4.00(0.44-35.78)$ \\
\hline Alcohol abuse & $9(16.7)$ & $5(9.3)$ & $1.125^{+}$ & 1 & 0.289 & $3.00(0.60-14.86)$ \\
\hline \multicolumn{7}{|l|}{ SCID-I } \\
\hline Affective psychosis & $24(44.4)$ & $23(42.3)$ & $<0.000^{\ddagger}$ & 1 & 1 & $1.20(0.36-3.93)$ \\
\hline \multicolumn{7}{|l|}{ Diagnosis } \\
\hline Bipolar disorder & $16(29.6)$ & $17(31.5)$ & $<0.000^{+}$ & 1 & 1 & $1.20(0.36-3.93)$ \\
\hline Psychotic depression & $8(14.9)$ & $5(9.3)$ & $0.5^{\ddagger}$ & 1 & 0.5 & $4.00(0.44-35.78)$ \\
\hline Schizophreniform disorder & 12 (22.2) & $1(1.9)$ & $9.901^{\ddagger}$ & 1 & $<0.001$ & - \\
\hline Schizophrenia & $13(24.1)$ & $25(46.3)$ & $8.643^{\ddagger}$ & 1 & 0.002 & $13.00(1.70-99.37)$ \\
\hline Schizoaffective disorder & $5(9.3)$ & $0(0.0)$ & $3.2^{*}$ & 1 & 0.063 & - \\
\hline \multicolumn{7}{|l|}{ PANSS } \\
\hline \multicolumn{7}{|l|}{ Symptom typology } \\
\hline Positive & $10(18.5)$ & $4(7.4)$ & $2.083^{\ddagger}$ & 1 & 0.146 & $3.00(0.81-11.08)$ \\
\hline Negative & $11(20.4)$ & $7(13.0)$ & $0.643^{\ddagger}$ & 1 & 0.424 & $1.80(0.60-5.37)$ \\
\hline Mixed & $13(24.1)$ & $4(7.4)$ & 4.923 & 1 & 0.022 & $5.50(1.21-24.81)$ \\
\hline None & $20(37.0)$ & 39 (72.2) & $12.00^{+}$ & 1 & 0.001 & $5.75(1.98-16.62)$ \\
\hline \multicolumn{7}{|l|}{ Scores, mean (SD) } \\
\hline Positive & $18.2(4.36)$ & $12.19(5.58)$ & $-5.309^{\dagger}$ & & $<0.001$ & 0.50 \\
\hline Negative & $21.63(7.83)$ & $16.74(6.86)$ & $-4.481^{\dagger}$ & & $<0.001$ & 0.42 \\
\hline General psychopathology & $38.70(7.5)$ & $32.07(8.30)$ & $4.85^{\S}$ & 53 & $<0.001$ & 0.55 \\
\hline
\end{tabular}

Data presented as $\mathrm{n}(\%)$, unless otherwise specified.

$\mathrm{DF}=$ degrees of freedom; $\mathrm{ECl}=$ Experience of Caregiving Inventory; PANSS = Positive and Negative Syndrome Scale; SCID-I = Structured Clinical Interview I; SD = standard deviation; SF-36 = Short-Form 36; SRQ-20 = Self-Report Questionnaire.

Bold type indicates statistical significance.

* Expressed as $r$ (for Wilcoxon signed-rank test or paired $t$ test) or odds ratio with $95 \%$ confidence interval (for McNemar test).

Wilcoxon signed-rank test (exact Monte Carlo), Z.

$¥$ McNemar test.

${ }^{\S}$ Paired $t$ test.

\section{Investigation of QoL predictors}

\section{Relationship between measures}

This study tested several variables based on QoL predictors identified as such in the literature. ${ }^{32,33}$ There were significant correlations between Essential QoL at 1-year follow-up and baseline SRQ scores $(r=-0.751)$ and PANSS negative symptom scale $(r=-0.253 ; \mathrm{p}=$ $0.023)$, positive symptom scale $(r=-0.238 ; p=0.033)$, and general psychopathology scale scores $(r=-0.250$; 


\begin{tabular}{|c|c|c|c|c|}
\hline Outcome/model path & Coefficient & SE & $p$-value & $95 \% \mathrm{Cl}$ \\
\hline \multicolumn{5}{|l|}{$\mathrm{ECl}$ negative score } \\
\hline Constant & -7.424 & 12.148 & 0.5438 & -31.80 to -16.95 \\
\hline Path a, SRQ-20 row score & 2.357 & 1.200 & 0.0549 & -0.0512 to 4.76 \\
\hline Covariate, $\mathrm{ECl}$ negative score - t0 & 0.6241 & 0.1344 & $<0.001$ & 0.3545 to 0.8937 \\
\hline \multicolumn{5}{|l|}{ Quality of life } \\
\hline Path $b, E C l$ negative score $-\mathrm{t} 1$ & -0.008 & 0.0026 & 0.0037 & -0.0134 to -0.0027 \\
\hline Path c, SRQ-20 row score & -0.131 & 0.0237 & $<0.001$ & -0.1786 to -0.0834 \\
\hline Covariate, $\mathrm{ECl}$ negative score - to & -0.0004 & 0.003 & 0.8894 & -0.0065 to 0.0057 \\
\hline
\end{tabular}

$p=0.025)$. These are clinically translated by relationships between QoL and depression or anxiety symptoms (in the caregiver) and severity of negative, positive, and general psychotic symptoms (in the patient). There was also a statistically significant, strong negative correlation between Essential QoL and the negative subscale of the $\mathrm{ECl}(r=$ $-0.251 ; p=0.240)$, but not the positive subscale $(r=-0.072$; $p=0.527$ ), indicating an association between $Q o L$ and the caregiver's negative appraisal of the caregiving experience.

\section{Regression models}

The primary goal of this study was to investigate which variables at baseline could predict the caregivers' Essential QoL at 1-year follow-up. A worse Essential QoL at 1-year follow-up was significantly associated with high scores on the SRQ-20, high scores on the negative subscale of the $\mathrm{ECl}$, and with the caregiver being the patient's mother on bivariate analyses. All variables were included in the same regression model. A high SRQ-20 score was the only significant predictor of the dependent variable Essential QoL at 1-year follow-up $(B=-0.149 ; p<0.001)$. Therefore, the analysis indicates depression and anxiety symptoms in the caregiver at baseline are associated with worse Essential QoL at 1-year follow-up.

\section{Mediation model}

A mediation model (Figure 1) was constructed to evaluate the impact of the relationship between variables on the caregivers' Essential QoL. We hypothesized that the negative subscale of the $\mathrm{ECl}$ would modulate the impact of the SRQ-20 on Essential QoL. The clinical effect of this hypothesis is that a negative perception of the caregiving experience would be associated with worse QoL, i.e., a larger number of depression and anxiety symptoms. Both the direct and indirect effect were significant (direct effect $=-0.131 ; p$ $<0.001 ; 95 \% \mathrm{Cl}=-0.178$ to -0.083 ; indirect point estimate = $-0.019,95 \%$ bootstrap $\mathrm{Cl}=-0.045$ to -0.033 ). This result suggests that the negative subscale of the $\mathrm{ECl}$ is partly responsible for the known effect of SRQ-20 on Essential QoL, though the SRQ-20 also affects Essential QoL directly. Non-standardized coefficients, $p$-values, and their respective 95\% Cls are given in Table 5.

\section{Discussion}

FEP is an important stressor that changes the family and home dynamic. Caregivers of patients in FEP experience perplexity, fear, concern, insecurity, denial, and doubt, but also faith, hope, solidarity, and love. ${ }^{2}$ It is clear that caregivers require assistance since the onset of illness.

This study chose QoL as a tool to evaluate the general health of caregivers through a well-established and globally validated scale of self-reported physical and mental wellbeing that is easily applied by services specialized in FEP. The strongest predictor of worse caregiver QoL at 1 -year follow up was psychological morbidity at baseline. The caregivers' depression and anxiety symptoms negatively influenced their self-assessment of the caregiving experience. Perceiving the caregiving experience as negative was associated with lower QoL. At baseline, the most affected QoL domains were role-emotional, vitality, and pain. At 1-year follow up, the 55 caregivers remaining in the study showed significant improvement in the QoL domains of emotional aspects, social aspects, and mental health. The most impaired QoL domain was pain, which is consistent with the alleged "somatization trait" of Latin cultures, possibly more associated with cultural and linguistic expression than with ethnicity. ${ }^{34}$ The prevalence of psychological morbidity among caregivers at baseline was $33.8 \%$, which is within the expected range (12-77\%) for caregivers of patients with psychotic disorders. ${ }^{3,35,36}$ However, the extreme variability of data from previous studies is remarkable. These disparities may be due to methodological or sampling differences, and thus must be viewed with caution.

The results of this study and daily clinical experience over the years in our outpatient service specialized in FEP indicate that the caregivers have an acute need for rapid, effective support, and gladly accept it when offered. Taking care of those who take care of the patient must be an essential part of any FEP treatment program from the outset. According to our study, initial evaluation of the caregiver must focus especially on symptoms of depression and anxiety, which must be identified and treated, and on the caregiver's self-assessment of the caregiving experience, in which positive aspects should be reinforced and negative aspects adequately approached.

Those few scientific studies that have focused on caregivers of individuals in FEP ${ }^{16,17}$ have generally shown suffering and anguish, although different aspects of the caregiving experience can be highlighted. ${ }^{3,7}$ The literature suggests that the caregiver's mental health and selfassessment of the caregiving experience may be more important for treatment than a family tie with the patient, even though being the patient's mother contributed to 
caregiver adherence in our sample, as did higher family income and better caregiver QoL at baseline. Therefore, caregivers, especially those who are not the patient's mother, must receive special attention to ensure higher adherence and thus improve outcomes of FEP treatment.

One limitation of this study is its nonrandomized sample. Inasmuch as FEP is not a diagnostic category, but a term used to characterize diagnoses, selected patients had to display at least one typical psychotic symptom such as delusions, disordered thought, or catatonia. The sample was not representative of the population of caregivers to patients in FEP in Brazil because the study was conducted in a public outpatient service affiliated with a large university hospital in the city of São Paulo. The sample size allowed only moderate to large effects. Nonetheless, we were able to find significant predictors of caregiver QoL.

Another issue was our approach to analysis of the eight SF-36 domains in a structured fashion. Recent literature in psychometrics indicates that the general attributes measured by any scale are more reliable than the scores of its subscales, with stronger reliable variance, including these dimensions of the SF- $36 .{ }^{37,38}$ This study used the innovative PCA method to extract a single QoL measure, considering the SF-36 has two dimensions that could be primarily explored (physical and mental health) and eight total dimensions. This approach may seem complicated for the non-specialist, but state-of-the-art statistical approaches were used to present robust findings in this study.

To the best of our knowledge, this is the first study on QoL of caregivers to individuals in FEP in Brazil. The longitudinal design incorporating innovative statistical analyses and models built on a solid theoretic foundation allowed evaluation of associations between different phenomena in a methodologically robust fashion.

We made a conscious effort to use well-established instruments in this study. The ECl has been used extensively in schizophrenia and FEP research, including assessments of the caregiving experience from the caregiver's point of view and involving positive and negative aspects. The SRQ-20 provides rapid, user-friendly screening for non-psychotic psychiatric disorders, particularly depression and anxiety. Finally, the SF-36 is a well-established QoL scale used all over the world.

We believe the findings of this study can contribute to the literature on caregivers of persons in FEP and the factors that predict QoL in this caregiver population. Furthermore, this investigation can help inform family interventions that are adapted to the Brazilian context and focused on the needs of this group. Clinical services focusing on FEP can and must provide early and continuous attention to caregivers who display symptoms of depression or anxiety, or who self-report a negative caregiving experience. This care will help maintain high caregiver QoL and increase the odds of higher treatment adherence by patients.

\section{Acknowledgements}

This study was supported by Fundação de Amparo à Pesquisa do Estado de São Paulo (FAPESP; grant
2008/10635-5) and by Coordenação de Aperfeiçoamento de Pessoal de Nível Superior (CAPES).

\section{Disclosure}

The authors report no conflicts of interest.

\section{References}

1 Martens L, Addington J. The psychological well-being of family members of individuals with schizophrenia. Soc Psychiatry Psychiatr Epidemiol. 2001;36:128-33.

2 Goncalves-Pereira M, Xavier M, van Wijngaarden B, Papoila AL, Schene AH, Caldas-de-Almeida JM. Impact of psychosis on Portuguese caregivers: a cross-cultural exploration of burden, distress, positive aspects and clinical-functional correlates. Soc Psychiatry Psychiatr Epidemiol. 2013;48:325-35.

3 Jansen JE, Lysaker PH, Harder S, Haahr UH, Lyse HG, Pedersen $\mathrm{MB}$, et al. Positive and negative caregiver experiences in first-episode psychosis: emotional overinvolvement, wellbeing and metacognition. Psychol Psychother. 2014;87:298-310.

4 Koutra K, Vgontzas AN, Lionis C, Triliva S. Family functioning in first-episode psychosis: a systematic review of the literature. Soc Psychiatry Psychiatr Epidemiol. 2014;49:1023-36.

5 Breitborde NJ, Srihari VH, Woods SW. Review of the operational definition for first-episode psychosis. Early Interv Psychiatry. 2009;3: 259-65.

6 Litzelman K, Skinner HG, Gangnon RE, Nieto FJ, Malecki K, Witt WP. Role of global stress in the health-related quality of life of caregivers: evidence from the survey of the health of Wisconsin. Qual Life Res. 2014;23:1569-78.

7 Addington J, Coldham EL, Jones B, Ko T, Addington D. The first episode of psychosis: the experience of relatives. Acta Psychiatr Scand. 2003;108:285-9.

8 Dillehay RC, Sandys MR. Caregivers for Alzheimer's patients: what we are learning from research. Int J Aging Hum Dev. 1990;30:263-85.

9 Treasure J, Murphy T, Szmukler G, Todd G, Gavan K, Joyce J. The experience of caregiving for severe mental illness: a comparison between anorexia nervosa and psychosis. Soc Psychiatry Psychiatr Epidemiol. 2001;36:343-7.

10 de Almeida Fleck MP. A avaliçao de qualidade de vida: guia para profissionais da saude. Porto Alegre: Artmed; 2008.

11 The World Health Organization Quality of Life assessment (WHOQOL): position paper from the World Health Organization. Soc Sci Med. 1995;41:1403-9.

12 Zhu P, Fu JF, Wang B, Lin J, Wang Y, Fang NN, et al. Quality of life of male spouse caregivers for breast cancer patients in China. Asian Pac J Cancer Prev. 2014;15:4181-5.

13 Mousavi B, Seyed Hoseini Davarani SH, Soroush M, Jamali A, Khateri S, Talebi M, et al. Quality of life in caregivers of severely disabled war survivors. Rehabil Nurs. 2015;40:139-47.

14 Mizuno E, Iwasaki M, Sakai I, Kamizawa N. Sense of coherence and quality of life in family caregivers of persons with schizophrenia living in the community. Arch Psychiatr Nurs. 2012;26:295-306.

15 Boyer L, Caqueo-Urizar A, Richieri R, Lancon C, Gutierrez-Maldonado J, Auquier P. Quality of life among caregivers of patients with schizophrenia: a cross-cultural comparison of Chilean and French families. BMC Fam Pract. 2012;13:42.

16 Margetic BA, Jakovljevic M, Furjan Z, Margetic B, Marsanic VB. Quality of life of key caregivers of schizophrenia patients and association with kinship. Cent Eur J Public Health. 2013;21:220-3.

17 Kate N, Grover S, Kulhara P, Nehra R. Relationship of caregiver burden with coping strategies, social support, psychological morbidity, and quality of life in the caregivers of schizophrenia. Asian J Psychiatr. 2013;6:380-8

18 Keshavan MS, Schooler NR. First-episode studies in schizophrenia: criteria and characterization. Schizophr Bull. 1992;18:491-513.

19 First MBS, Willians JBW, Gibbon M. Structured Clinical Interview for DSM-IV Axis I Disorders (SCID-I). Handbook of psychiatric measures. Washington: American Psychiatric Association; 2000. 
20 Kay SR, Fiszbein A, Opler LA. The positive and negative syndrome scale (PANSS) for schizophrenia. Schizophr Bull. 1987;13:261-76.

21 Vessoni A. Adaptação e estudo de confiabilidade da escala de avaliação das síndromes positiva e negativa para a esquizofrenia no Brasil [thesis]. São Paulo: Universidade Federal de São Paulo; 1993.

22 Ciconelli RM Ferraz MB. Santos W, Meinão I, Quaresma MR. Tradução para a língua portuguesa e validação do questionário genérico de avaliação de qualidade de vida SF-36 (Brasil SF-36). Rev Bras Reumatol. 1999;39:143-50.

23 Joyce J, Leese M, Kuipers E, Szmukler G, Harris T, Staples E. Evaluating a model of caregiving for people with psychosis. Soc Psychiatry Psychiatr Epidemiol. 2003;38:189-95.

24 Harding TW, de Arango MV, Baltazar J, Climent CE, Ibrahim $\mathrm{HH}$, Ladrido-Ignacio $\mathrm{L}$, et al. Mental disorders in primary health care: a study of their frequency and diagnosis in four developing countries. Psychol Med. 1980;10:231-41.

25 Ware JE Jr, Sherbourne CD. The MOS 36-item short-form health survey (SF-36). I. Conceptual framework and item selection. Med Care. 1992;30:473-83.

26 Szmukler GI, Burgess P, Herrman H, Benson A, Colusa S, Bloch S. Caring for relatives with serious mental illness: the development of the experience of caregiving inventory. Soc Psychiatry Psychiatr Epidemiol. 1996;31:137-48.

27 Jorge Rde C, Chaves AC. The experience of caregiving inventory for first-episode psychosis caregivers: validation of the Brazilian version. Schizophr Res. 2012;138:274-9.

28 Cattell RB. The scree test for the number of factors. Multivariate Behav Res. 1966;1:245-76.

29 Caqueo-Urizar A, Gutierrez-Maldonado J. Burden of care in families of patients with schizophrenia. Qual Life Res. 2006;15:719-24.
30 Hayes AF. Introduction to mediation, moderation, and conditional process analysis: a regression-based aproach. New York: Guilford; 2013.

31 Hayes AF. Beyond Baron and Kenny: statistical mediation analysis in the new millennium. Commun Monogr. 2009;76:408-20.

32 Wong DF, Lam AY, Chan SK, Chan SF. Quality of life of caregivers with relatives suffering from mental illness in Hong Kong: roles of caregiver characteristics, caregiving burdens, and satisfaction with psychiatric services. Health Qual Life Outcomes. 2012; 10:15.

33 Li J, Lambert CE, Lambert VA. Predictors of family caregivers' burden and quality of life when providing care for a family member with schizophrenia in the People's Republic of China. Nurs Health Sci. 2007;9:192-8.

34 Tófoli LF, Andrade LH, Fortes S. Somatization in Latin America a review of the classification of somatoform disorders, functional syndroms and medically unexplained symptoms. Rev Bras Psiquiatr. 2011;33:S59-80.

35 The Scottish First Episode Schizophrenia Study. IV. Psychiatric and social impact on relatives. The Scottish Schizophrenia Research Group. Br J Psychiatry. 1987;150:340-4.

36 Tennakoon L, Fannon D, Doku V, O'Ceallaigh S, Soni W, Santamaria $\mathrm{M}$, et al. Experience of caregiving: relatives of people experiencing a first episode of psychosis. Br J Psychiatry. 2000;177:529-33.

37 Reise SP, Bonifay WE, Haviland MG. Scoring and modeling psychological measures in the presence of multidimensionality. J Pers Assess. 2013;95:129-40.

38 Rodriguez A, Reise SP, Haviland MG. Applying bifactor statistical indices in the evaluation of psychological measures. J Pers Assess. 2016;98:223-37 